\title{
Carnets
}

Revue électronique d'études françaises de l'APEF

Première Série - 1 Numéro Spécial | 2009

Cultures littéraires : nouvelles performances \& développement

\section{Uma nova abordagem interdisciplinar: da Escrita Criativa aos Estudos Crítico-Criativos}

\section{João de Mancelos}

\author{
(CpenEdition \\ Journals \\ Edição electrónica \\ URL: http://journals.openedition.org/carnets/3924 \\ DOI: $10.4000 /$ carnets.3924 \\ ISSN: 1646-7698 \\ Editora \\ APEF
}

Edição impressa

Data de publição: 1 Junho 2009

Paginação: 257-265

Refêrencia eletrónica

João de Mancelos, « Uma nova abordagem interdisciplinar: da Escrita Criativa aos Estudos Crítico-

Criativos », Carnets [Online], Première Série - 1 Numéro Spécial | 2009, posto online no dia 16 junho

2018, consultado o 20 abril 2019. URL : http://journals.openedition.org/carnets/3924 ; DOI : 10.4000/ carnets.3924

Carnets est mis à disposition selon les termes de la licence Creative Commons - Atribution - Pas d'utilisation commerciale 4.0 International. 


\title{
UMA NOVA ABORDAGEM INTERDISCIPLINAR: \\ Da Escrita Criativa aos Estudos Crítico-Criativos
}

\author{
JOÃO DE MANCELOS \\ Universidade Católica Portuguesa \\ mancelos@gmail.com
}

\begin{abstract}
Resumo
Existe uma antipatia histórica entre as áreas dos Estudos Literários (EL) e da Escrita Criativa (EC) como disciplina académica. Os docentes de EC criticam os EL como sendo dogmáticos, rígidos e sustentados por uma terminologia complexa. Por seu turno, os especialistas em EL desconsideram a cadeira de EC, vista como experimental, ou demasiado baseada em técnicas e conselhos, e ainda recente nos curricula universitários. No entanto, cada vez mais, os docentes de EC compreendem a necessidade de recorrer aos EL, para melhor formar os jovens aspirantes a escritores: refiro-me a conceitos; aspectos técnicos; noções de versificação e de narratologia; técnicas, etc. Estaremos a assistir ao desenvolvimento de uma nova área, os Estudos Crítico-Criativos? Neste artigo, baseado na minha experiência de escritor, docente de EL e de EC, tenciono demonstrar as vantagens desta abordagem interdisciplinar
\end{abstract}

\begin{abstract}
There is an historical antipathy between Literary Theory (LT) and Creative Writing (CW) as an academic subject. CW teachers see LT as dogmatic, rigid and with a complex jargon. On the other side, LT specialists dismiss CW as a merely experimental area, comparatively young in academic curricula. However, a growing number of $\mathrm{CW}$ teachers understand the absolute need to resort to LT, to better teach young aspiring writers. I am referring to concepts; technical aspects; notions related to versification and narratology; techniques, etc. Are we watching the development of a new field, the Creative and Critical Studies? In this paper, based upon my experience as a writer, and a Literary Studies and CW teacher, I intend to demonstrate the benefits of this interdisciplinary approach.
\end{abstract}

Palavras-chave: Estudos literários, Escrita criativa, Creative and critical studies Keywords: Literary studies, Creative writing, Creative and critical studies 
The pages are still blank,

but there is a miraculous feeling of the words being there, written in invisible ink and clamoring to become visible.

Vladimir Nabokov (1899-1977)

\section{A Escrita Criativa e a Interdisciplinaridade}

Em 1210, o monge e poeta inglês Geoffrey de Vinsauf redigiu Poetria Nova, um livro que muitos consideram ser o primeiro manual de Escrita Criativa. Trata-se de uma composição métrica com mais de dois mil versos, em latim, onde o autor explica estratégias para escrever, aconselha os jovens, e sugere exercícios que ainda hoje podem ser usados, com êxito pedagógico, numa oficina (Morley, 2007: 17). Vinsauf não estava sozinho nas suas preocupações: os poetas e prosadores sempre souberam que só o talento, perseverança e iniciativa não bastam para produzir uma obra de excepção. Como tal, partilharam com os aprendizes do ofício da escrita - através de cartas, biografias, entrevistas, ensaios, e conversas mais ou menos informais - um aspecto essencial a qualquer arte: a técnica.

$\mathrm{Na}$ actualidade, com a disseminação dos cursos de Escrita Criativa, os especialistas ensinam estratégias de um modo mais organizado, e discutem a afinidade desta área do saber artístico com outros campos académicos. Wallace Stevens (1879-1955) foi um dos autores norte-americanos que reflectiram acerca da arte da ficção e da poesia. No texto "Les Plus Belles Pages" - o título original é em Francês -, afirma: "Nothing exists by itself" (Stevens, 1997: 222). Estas quatro palavras constituem um mote para a interdisciplinaridade, e descrevem com precisão o panorama académico contemporâneo. Existe uma urgência em partilhar e consolidar o saber; em debater aspectos comuns aos diversos campos; em explorar o território ainda desconhecido que se estende entre estes.

No entanto, houve determinadas disciplinas que viveram de costas voltadas durante décadas, procurando encontrar a identidade pela diferença, e enfatizando mais as oposições que as similitudes. A Escrita Criativa, desde a sua inclusão nos curricula académicos, em 1880, por Barrett Wendell, no Harvard College, até recentemente, tem demonstrado uma antipatia histórica em relação à Teoria da Literatura como área académica (Ramey, 2007: 43). A primeira vaga de especialistas em Escrita Criativa - que obtiveram o seu grau de licenciatura em universidades como Johns Hopkins, Denver, lowa e Stanford, nos anos quarenta e cinquenta - demonstrou uma atitude de rebeldia e uma cultura de anti-intelectualismo em relação à academia. Por exemplo, ao peso da tradição da Teoria da Literatura, os professores respondiam com o conceito de oficina; à análise crítica da arte contrapunham a produção literária; e defendiam a descentralização da autoridade do 
docente, criando uma espécie de "literary café", onde as ideias fluíam e onde cada aluno podia criticar os restantes (Swander, Leahy, e Cantrell, 2007: 18).

Um dos membros mais prestigiados dessa geração foi Paul Engle, que obteve o seu grau de mestre na área da Escrita Criativa, em 1932, na University of lowa, com uma tese intitulada Worn Earth, vencedora do Younger Poets Award. Engle juntou-se ao corpo docente da referida universidade em 1937, e tornou-se, o director oficial do lowa Writers Workshop. O seu objectivo era ambicioso, como explicava numa carta datada de 1963 ao presidente da universidade: "to run the future of American literature, and a great deal of European and Asian, through lowa City" (Swander, Leahy, e Cantrell, 2007: 12). Engle tomou decisões que ainda hoje têm impacto na estruturação e objectivos da Escrita Criativa: dividiu a oficina em géneros (poesia e ficção); criou um sentimento comunitário entre os estudantes da oficina e o seu mentor; convidou Dylan Thomas (1914-1953), W. H. Auden (1907-1973) e Robert Frost (1874-1963) a coordenarem algumas das oficinas (Swander, Leahy, e Cantrell, 2007: 12). Tornou-se comum, portanto, a cadeira ser dirigida por escritores conceituados e vencedores de prémios nacionais; no entanto, regra geral, estes não eram especialistas em estudos críticos. Tal cavava um fosso cada vez mais amplo entre a Escrita Criativa e a Teoria da Literatura e fazia perder de vista a relação interdisciplinar.

De facto, há uma interligação entre as duas disciplinas, feita de antecedentes, métodos semelhantes, e o mesmo campo de estudo: a Literatura. Progressivamente, as instituições de ensino superior que oferecem cadeiras de Escrita Criativa compreendem a necessidade de recorrer a conhecimentos leccionados na Teoria da Literatura, para melhor formar os jovens aspirantes a escritores, e, por consequência, os futuros docentes da área.

\section{A inspiração do conhecimento}

Por certo, em qualquer oficina de Escrita é importante conhecer a teoria e os critérios de análise e de selecção de textos literários, ao longo dos séculos. Segundo os ensaístas Donald Morton e Mas'ud Zavarzadeh:

The Creative Writing student who knows theory and who has read Marx, Lacan, Foucault, Lenin, Kristeva, Derrida, Gramsci, Heidegger, Cixous, Deleuze, Althusser, Luxemburg, Adorno will not approach the workshop with the same naïveté or accept the orthodoxies as will the student who has read the traditional syllabus of the literature department, which is entirely composed of poems, novels and stories. (Morton e Zavarzadeh, 1988: 155) 
Também é indispensável conhecer a tradição literária nacional e internacional onde o autor se insere. Certos estudantes de Escrita Criativa argumentam que as grandes obras os inibem ou influenciam em demasia: afirmam que um jovem escritor se sente esmagado pela qualidade realista das quinhentas e cinquenta e nove personagens de Guerra e Paz, de Leo Tolstoy (1828-1910), ou bloqueia perante a perfeição de um soneto de William Shakespeare (1564-1616), onde cada palavra foi escolhida com cuidado pelo seu significado e sonoridade. Segundo alguns alunos, uma opção radical seria até nada ler, para tentarem encontrar, nesse isolamento, uma voz única - como se a originalidade total, no mundo literário, fosse possível... Discordo da posição destes estudantes: a minha experiência levame a acreditar que conhecer os grandes autores é inspirador; melhora o estilo; alarga o vocabulário; permite perceber a evolução de um género; compreender as novas tendências que nele operam; oferece modelos e exemplos das técnicas essenciais.

Para tanto, a actividade de escrita deve ser acompanhada da chamada leitura criativa. Tal consiste em ler um texto de forma atenta, não apenas para melhor o fruir, mas também para compreender a sua orgânica e tentar perceber como o autor conseguiu obter um determinado efeito. O lexicógrafo e escritor inglês Samuel Johnson (1709-1884) argumentou: "The greatest part of a writer's time is spent in reading in order to write; a man will turn over half a library to make one book" (Boswell, 1992: 541).

O oposto - escrever para ler melhor - também ocorre. Um estudante que conheça as técnicas da elaboração de um soneto, por exemplo, é capaz de interpretar com maior profundidade um destes textos; de apreciar o talento e o esforço desenvolvidos pelo autor; de avaliar o poema com conhecimento crítico. Como explica Jon Cook, director do Centre of Creative and Performing Arts, na University of East Anglia.:

For example, writing sonnets is a way of learning how to read them. The sonnet form can be built up, one step at a time, by exercises in rhyme and meter. [...] Testing this out first-hand can give an insight into how the form worked, which no amount of enquiry into discourses of power in Elizabethan England can provide. The main purpose of the exercise is not to write a brilliant sonnet, although that may happen, but to complement critical enquiry with some creative experiment, to understand a literary form in terms of craft and technique, both compositional act and cultural process. (Cook, 2001: 300)

O escritor necessita de dominar determinados conceitos estudados nas aulas de Teoria da Literatura, essenciais ao trabalho do escritor, como sejam:

a) A ficcionalidade e a relação entre o mundo real e o do texto;

b) A intertextualidade explícita ou implícita; 
c) A importância e inevitabilidade da influência - uma das obsessões dos escritores aprendizes, que se preocupam em não conseguirem "dizer algo de novo". Harold Bloom descreveu com precisão este sentimento no seu best-seller académico The Anxiety of Influence: A Theory of Poetry (1973), e também o explicou em A Map of Misreading (1975):

A poet is not so much a man speaking to men as a man rebelling against being spoken to by a dead man (the precursor) outrageously more alive than himself. A poet dare not regard himself as being late, yet cannot accept a substitute for the first vision he reflectively judges to have been the precursor's also. (Bloom, 1975: 19)

Qualquer um destes conceitos ajuda a definir a essência de um texto literário, e revela a sua dinâmica no contexto geral da literatura, por relação com outras obras. É importante conhecer:

a) As épocas literárias, para ficar ciente da evolução e tendência de cada género, para seguir ou, melhor ainda, reinventar essas direcções;

b) As diferenças, características, e códigos de composição dos vários géneros;

c) Noções de narratologia (a tipologia do narrador, por exemplo), e as diferenças que resultam de contar uma história de acordo com este ou aquele ponto de vista;

d) Os trinta e um narratemas, tal como especificados pelo formalista russo Vladimir Propp (1895-1970), essenciais para criar unidades narrativas, tipos e personagens, de acordo com as funções que desempenham no enredo;

e) Os vários tipos de espaço e de ambiente, e as possibilidades simbólicas que oferecem no seio de uma narrativa;

f) A manipulação do tempo (analepses, prolepses, elipses), tão importante para romancistas mais experimentais. Escritores como William Faulkner (1897-1962) ou Toni Morrison (1931), por exemplo, recorreram com tanta frequência a analepses, prolepses, e até a enredos em forma de espiral, que estas estratégias se tornaram marcas facilmente reconhecíveis do seu estilo;

g) Técnicas de versificação (rima, ritmo, sonoridade, etc.);

h) Figuras de estilo: metáfora, metonímia, sinédoque, ironia, paradoxo, oximoro, hipérbole, etc. O poder de uma metáfora ou comparação, por exemplo, é significativo, como qualquer escritor sabe. Estas podem ser usadas para descrever um sentimento ("Ela sentiase como se valesse um milhão de dólares"); criar uma atmosfera ("O céu estava enevoado, e deixava cair sobre as encruzilhadas sujas uma luz desencorajadora"); ou caracterizar uma personagem ("O rapaz era uma lâmpada de 15 watts") (Stein, 2003: 265-67).

Um aluno que não domine esta linguagem técnica será como um ferreiro que ignora o nome dos instrumentos que utiliza na sua profissão, e corre o risco de não conseguir moldar convenientemente o metal para obter uma obra perfeita. Revi estas matérias com os 
meus alunos de Escrita Criativa no Mestrado em Comunicação e Expressão, decorrido na Universidade Católica Portuguesa, em Viseu, no ano lectivo de 2004/05. Foi a primeira cadeira desta área a fazer parte do elenco de uma pós-graduação em Portugal, e dela resultou uma dissertação de Mestrado sobre Escrita Criativa, feita por Cláudia Catarina Costa, sobre técnicas aplicadas à arte do romance. O objectivo da dita revisão era contextualizar cinco passos fundamentais na aprendizagem do ofício da escrita: conhecer, exemplificar, debater, aplicar e avaliar as técnicas utilizadas na elaboração de um texto ficcional.

Para além desses aspectos, o escritor aprendiz deve também dominar métodos de pesquisa, para escrever um romance histórico, ou para investigar acerca de um lugar ou de uma profissão a atribuir a uma personagem. É um equívoco comum pensar que um escritor inventa ou cria a partir do zero; o que efectivamente faz é recorrer a pessoas ou lugares que conhece, ou com os quais se cruzou nalgum momento da sua vida, e mudá-los ou mesmo subvertê-los, para os tornar mais apelativos ao leitor e relevantes para a história. Muitas vezes, pesquisa em bibliotecas, ou utiliza os recursos da Internet, ou ainda efectua trabalho de campo, conversando com outras pessoas e visitando locais. Entre outras disciplinas académicas, a Teoria da Literatura pode ser um precioso auxiliar, pois incute nos estudantes hábitos de pesquisa, e sentido de rigor.

A Escrita Criativa é passível de ser ensinada no contexto de outras disciplinas. Por exemplo, enquanto professor de Introdução aos Estudos Literários, estabeleci uma unidade didáctica de técnicas para elaborar narrativas breves, bastante popular entre os alunos, e estrategicamente posicionada no final do ano lectivo, quando os estudantes já dominavam conhecimentos de Teoria da Literatura. Essas aulas mostravam a utilidade prática das matérias apreendidas, e serviam também para as exercitar.

A Escrita Criativa não é apenas útil a escritores e poetas; interessa a jornalistas, biógrafos e mesmo a académicos. Nos últimos anos, verifica-se uma tendência nítida, nos manuais desta área, para incluir um capítulo onde se exploram técnicas aplicadas ao texto não ficcional. Num ensaio académico ou numa comunicação para um congresso, por exemplo, o autor aprende a usar estratégias de Escrita Criativa para motivar o leitor, gerar suspense, e estruturar as ideias com clareza. De acordo com o romancista Sol Stein:

Like fiction, nonfiction accomplishes its purpose better when it evokes emotion in the reader. We might prefer everyone on earth to be rational, but the fact is that people are moved more by what they feel than by what they understand. Great orators as well as great nonfiction writers have always understood that. (Stein, 2003: 224) 


\section{O regresso do primo distante}

Apesar da sua utilidade tanto para escritores como para académicos, a Escrita Criativa foi vista, ao longo de demasiados anos, como o primo distante dos Estudos Literários (Ramey, 2007: 44). Hoje, esta disciplina adquire visibilidade e torna-se credível nos círculos universitários, graças a cada vez mais programas de Mestrado e de Doutoramento. Tal implica uma maior especialização dos professores e dos estudantes, bem como um conhecimento substancial dos conteúdos e métodos de investigação aprendidos em Teoria da Literatura.

A ligação pedagógica, o diálogo profícuo e a polinização de ideias não trazem apenas vantagens para a cadeira de Escrita Criativa. Há numerosas matérias que interessam simultaneamente aos escritores aprendizes e aos alunos de Teoria da Literatura. Por exemplo, na oficina podem abordados, do ponto de vista de um artista, aspectos como a morte do autor, a receptividade de um texto ou a canonização (Dawson, 2007: 81). O debate pode contar até com a presença de estudantes e professores de ambas as disciplinas, gerando uma fértil troca de ideias, opiniões e perspectivas, num ambiente académico de partilha de conhecimento.

Tive a oportunidade de experimentar a dinâmica que resulta da combinação dos campos adjacentes da Escrita Criativa e dos Estudos Literários, durante um mês, em 2004. Sabendo que leccionaria Escrita Criativa, no ano lectivo seguinte, aos estudantes de pósgraduação, inscrevi-me num curso de Verão da Universidade de Luton, no Reino Unido, não apenas porque esta tinha uma excelente reputação, mas também porque foi o primeiro estabelecimento de ensino na Europa a transformar a secção de Estudos Literários num Departamento de Média e Artes, em 1998 (Ramey, 2007: 46). Esta decisão foi tomada para fazer face à crise de humanidades, que afecta as escolas no Velho Continente.

Em Luton, aprendi estratégias com Jill Barker, Marc Lavelle e Keith Jebb, professores de Literatura, e especialistas, respectivamente, em poesia, peças radiofónicas, e narrativa ficcional. No todo, foi uma experiência enriquecedora, dado que tomei uma consciência mais profunda das técnicas que já usava, e adquiri outras; como estudante, fiz exercícios que, mais tarde, aplicaria nas minhas próprias aulas; e, finalmente, recebi retorno crítico aos meus textos, por parte de professores e colegas.

Interessava-me observar como se aplicavam os saberes dos Estudos Literários na oficina de escrita: foi reconfortante aperceber-me de que os métodos de Luton eram similares aos que eu usava, quando leccionava a unidade didáctica de escrita aos meus alunos de licenciatura. O objectivo geral era preparar cada aspirante a autor, transmitindoIhe um conhecimento sólido acerca da história e conceitos usados nos Estudos Literários, para que este se tornasse num escritor mais versátil. 
Tal confluência de saberes dará origem a especialistas que serão simultaneamente poetas e críticos, capazes de dinamizar a disciplina de Escrita Criativa e, ao mesmo tempo, de trazer uma lufada de ar fresco à Teoria da Literatura. No fim de contas, tal como Ernest Hemingway (1899-1961) afirmou, numa entrevista ao New York Journal-American (11 Julho de 1961), "We are all apprentices in a craft where no one ever becomes a master" (apud Morley, 2007: 11). 


\section{Bibliografia}

BLOOM, Harold (1975). A Map of Misreading. New York: Oxford University Press.

BoswelL, James (1992). Life of Johnson. New York: Random House.

Cook, Jon (2001). "A Brief History of Workshops". In: Julia Bells, Paul Magrs (eds). The Creative Writing Coursebook. London: Macmillan, pp. 296-303.

Dawson, Paul (2007). "The Future of Creative Writing". In: Steven Earnshaw (ed). The Handbook of Creative Writing. Edinburgh: Edinburgh University Press, pp. 78-90.

MORLEY, David (2007). The Cambridge Introduction to Creative Writing. Cambridge: Cambridge University Press.

MORTON, Donald and Mas'ud Zavarzadeh (1988). "The Cultural Politics of the Fiction Workshop". In: Cultural Critique, n. 11, pp. 155-73.

RAMEY, Lauri (2007). "Creative Writing and Critical Theory". The Handbook of Creative Writing. Ed. Steven Earnshaw. Edinburgh: Edinburgh University Press, pp. 42-53.

StEIN, Sol (2003). Solutions for Writers: Practical Craft Techniques for Fiction and Non-fiction. London: Souvenir Press.

SteVens, Wallace (1997). Collected Poetry \& Prose. New York: The Library of America.

SWANDER, Mary, Anna Leahy, and Mary Cantrell (2007). "Theories of Creativity and Creative Writing Pedagogy". In: Steven Earnshaw (ed). The Handbook of Creative Writing. Edinburgh: Edinburgh University Press, pp. 11-23. 